\title{
Técnicas de utilização de dicionário como material didático na aula de LE para fins específicos
}

\author{
Camila Höfling \\ UNESP/FCLar \\ Maria Cristina Parreira da Silva \\ UNESP/IBILCE \\ Patrícia Tosqui \\ UNESP/ROSANA
}

\begin{abstract}
Este artigo apresenta uma metodologia de trabalho relacionado ao uso do dicionário como material didático na aula de língua estrangeira com fins específicos, em atividades como desenvolvimento de vocabulário, gramática, pronúncia, uso de língua, cultura, leitura e interpretação de texto. Com certas técnicas, os professores podem aproveitar esse material em suas aulas e orientar seus alunos sobre qual dicionário adquirir e como empregá-lo de maneira eficiente. Oferecemos algumas sugestões de atividades para serem realizadas com o dicionário, seja em aulas para alunos particulares ou em cursos profissionalizantes em áreas específicas.
\end{abstract}

This paper presents a methodology related to the use of dictionary as a pedagogic resource in the foreign language for specific purposes class, in activities developing vocabulary, grammar, pronunciation, language use, culture, and reading comprehension. By using some techniques, teachers can benefit from this resource in class and instruct their students about how to choose and use a dictionary properly. We offer some suggestions of activities to be performed both in private classes (one-to-one) and with groups of professionals with specific purposes.

\section{Introdução}

Este trabalho tem como objetivo abordar atividades práticas para o uso de dicionários como ferramentas de estímulo à autonomia de alunos e usuários da língua estrangeira. Os materiais paradidáticos são muito eficientes como complemento ou substituição do material didático. Podem ser usados tanto em sala de aula quanto em atividades 
individuais (e de interesse pessoal) no ensino de línguas estrangeiras (LE). O dicionário constitui, sem dúvida, uma ótima fonte de informações. Trabalhos específicos, como traduções de texto para determinados fins, não prescindem de um bom dicionário. O que falta é conhecer os dicionários, aprender a usá-los corretamente, saber buscar cada tipo de informação e, acima de tudo, saber quando usar o dicionário.

Este trabalho está organizado da seguinte maneira: primeiramente, fazemos um comentário sobre a tendência, verificada nos cursos de língua estrangeira, de buscar o domínio de uma atividade ou fim específico como uma alternativa mais rápida e concentrada aos cursos de LE tradicionais. Em seguida, destacamos a importância do uso do dicionário como material didático na aula de língua estrangeira para fins específicos (de agora em diante LEFE). O professor deve conhecer os diferentes tipos de dicionários a fim de poder indicar o modelo mais apropriado às necessidades específicas de seus alunos. Passamos, então, a observar o perfil dos usuários de dicionários: quem são os alunos e profissionais que consultam dicionários? Para que fins? Apresentamos, para ilustrar, o caso do curso de LE para Turismo como um exemplo de fim específico. Essas questões são discutidas para que passemos à parte mais prática do artigo, em que são apresentadas possibilidades de trabalho com o dicionário na aula de LEFE.

\section{A procura por aulas de LEFE}

Dominar uma ou mais línguas estrangeiras, segundo Berchoud (2004), tornou-se uma obrigação profissional ligada à prática de atividades variadas. A globalização é a principal causa dessa nova exigência do mercado: há um crescente intercâmbio entre as nações, tanto no nível tecnológico quanto comercial. A linguagem se configura como a primeira barreira a ser transposta.

Conseqüentemente, hoje em dia há uma demanda muito expressiva de cursos e aulas particulares para fins específicos. Esse público diferenciado pretende atingir seus objetivos de maneira rápida e eficiente, como afirma Challe (2004), preferindo, para tanto, a aula particular (one-to-one). Dentre as diferentes razões para se buscar um aprendizado rápido e concentrado, voltado para necessidades práticas, podemos destacar: preparar-se para uma prova de proficiência em 
seleções de pós-graduação; ler e interpretar textos para cursar disciplinas de pós-graduação; preparar-se para entrevistas de emprego; desenvolver habilidades de comunicação em ambiente profissional e de negócios; comunicar-se com clientes, hóspedes ou turistas; aprender expressões gerais de situações comunicativas para fazer uma viagem ao exterior; explorar adequadamente os recursos da Internet e das mensagens eletrônicas, entre outros.

Apesar de a procura por cursos de língua inglesa com objetivos específicos dominar, hoje, o mercado, cada vez mais cursos de outras línguas são procurados, como espanhol, francês e italiano. Recentes pesquisas apontam até mesmo procura por línguas mais distantes do português, como japonês e chinês.

Além das aulas particulares, que costumam se destinar a uma pessoa ou a grupos com número muito reduzido de alunos, podemos constatar também o aumento de cursos universitários que oferecerem, em caráter obrigatório ou optativo, disciplinas de LE. A necessidade de se obterem conhecimentos em outra língua, voltados para o desempenho de atividades relacionadas a uma profissão específica, pode ser comprovada pelo aumento do número de cursos de nível superior que têm em sua grade, como disciplina obrigatória, a língua inglesa focada nas suas necessidades profissionais. Cursos como Turismo, Hotelaria e Secretariado Executivo Bilíngüe têm como exigência do MEC o domínio de, no mínimo, uma LE e, em geral, costumam oferecer inglês e espanhol. Outros cursos, como Ciências da Computação, Processamento de Dados, Publicidade e Propaganda, Jornalismo e Desenho Industrial também costumam oferecer inglês e, às vezes, espanhol em sua grade.

Quanto ao francês, embora se tenha sempre em mente o estereótipo de uma língua que encanta os ouvintes, a língua das artes e da cultura, apresenta-se com interesses específicos na área do comércio, ciência e tecnologia. A maioria dos aprendizes quer atender principalmente às necessidades de leitura para prestar exames de proficiência em francês para os cursos de mestrado e doutorado; leitura para compreensão de textos disponibilizados na Internet; leitura de obras originais para pesquisa; leitura e escrita de mensagens eletrônicas para fins particulares ou profissionais; comunicação nas relações comerciais entre empresas franco-brasileiras e empresas estabelecidas no Brasil cuja língua é o francês (provenientes da Ásia, África, Canadá 
etc.); comunicação (tradução e interpretação) em congressos com participação de especialistas francófonos; redação de resumos em francês para publicação em tese ou periódico, entre outras.

Esse direcionamento nas aulas de LE está gerando a necessidade de se realizarem mais pesquisas que analisem e explorem essa tendência. Esperamos, com este artigo, trazer uma modesta contribuição para a área, destacando o uso do dicionário na aula de LEFE.

\section{O dicionário na aula de LEFE}

Os alunos de língua estrangeira, muitas vezes, pedem a opinião do professor para escolher e adquirir seu dicionário. No caso do estudo de LEFE, isso não é diferente. Uma das atribuições do professor de LEFE é saber e ensinar a explorar com o especialista os dicionários ou vocabulários especializados, mesmo que encontre materiais deficientes. Por esse motivo, os educadores devem estar informados sobre os tipos e a qualidade das obras disponíveis no mercado, uma vez que há obras adequadas ao nível de aprendizagem, à faixa etária do aprendiz e ao uso específico da língua, por exemplo. É importante situar a obra a ser adquirida dentro de uma escala de parâmetros, que pode ser verificada pelo próprio aprendiz.

Observemos os principais itens a serem considerados na escolha de uma obra de referência (HAENSCH, 1981): 1. tipo de dicionário; 2. introdução elucidativa; 3 . data de publicação mais recente; 4. público visado; 5 . número de entradas; 6 . inclusão de termos de diferentes níveis lingüísticos; 7. apresentação da definição e/ou do equivalente; 8. transcrição fonética (de preferência feita com base no AFI - Alfabeto Fonético Internacional). Cabe ao professor conhecer bem os diferentes tipos de dicionário, não só para indicar o modelo mais adequado para cada um de seus alunos, mas também para propor atividades em sala de aula que ajudem os alunos a entrar nesse novo mundo que é o texto lexicográfico. Como já afirmamos em outro trabalho, "é preciso conviver com os dicionários, folheá-los e utilizá-los. Além de coadjuvante no ensino, usado nas tarefas fora da sala de aula, o dicionário pode ter um papel principal, tornando-se o próprio objeto de certas atividades que proporcionem o desenvolvimento lexical dos aprendizes" (HÖFLING; SILVA; TOSQUI, 2004, p. 4). 
Segundo Wright (1998), há seis tipos de atividades que têm como objetivo a familiarização do aprendiz com o uso do dicionário:

(1) atividades para um primeiro contato do aprendiz com o dicionário, como a introdução à terminologia básica e partes importantes de um dicionário. Trata-se de uma ferramenta importante para que o professor diagnostique problemas, preconceitos e crenças do aprendiz sobre o uso do dicionário;

(2) atividades com palavras-chave, ou seja, exercícios que levem em conta as diferentes partes do discurso, formação de palavras, símbolos fonéticos. Essas atividades habilitam o aprendiz a usar de forma correta os "códigos" utilizados nos verbetes;

(3) atividades com o significado, a definição apresentada no dicionário, a relação e a associação entre palavras;

(4) atividades que promovem o desenvolvimento do vocabulário do aprendiz (exercícios referentes a campos lexicais, expressões idiomáticas, colocações);

(5) atividades de compreensão de textos autênticos na língua estrangeira. O dicionário é visto como uma das estratégias de leitura aplicadas pelo aprendiz;

(6) atividades que focalizam uma comparação entre vantagens e desvantagens de se optar por dicionários monolíngües ou bilíngües em situações diferentes de aprendizagem.

Um aspecto que, apesar de normalmente não ser muito relacionado ao dicionário e que pode ser explorado por esse recurso, é o ensino de cultura. O professor deve desmistificar a crença do aprendiz de que não há fronteiras nos conhecimentos profissionais. Na realidade, ele deve incluir, em seu programa, reflexões sobre a dimensão cultural da comunicação, que certamente é divergente nas duas línguas em foco (SAGNIER, 2004). Embora o dicionário seja, via de regra, consultado para se verificarem aspectos lingüísticos (morfológicos, fonéticos, semânticos etc.), muitos modelos atuais trazem importantes dados culturais, quer seja caracterizando a cultura dos povos da língua em questão, no caso dos dicionários monolíngües, quer contrastando esses dados com a cultura da língua de chegada, no caso dos dicionários bilíngües. De acordo com Pandolfi e Tosqui (2004, p. 2), 
O conhecimento efetivo de uma LE implica, necessariamente, o estudo da cultura dos falantes dessa língua. Contudo, grande parte dos cursos de LE, pelas mais diversas razões, não privilegia o ensino da língua através da cultura, de forma integrada, sobretudo, porque os próprios materiais didáticos apresentam uma visão de que os alunos necessitam aprender primeiro os aspectos gramaticais e o léxico básico da língua para, futuramente, entrar em contato com materiais que tratam de cultura. Esse 'futuramente', para muitos, quase nunca acontece, seja por insegurança do professor, seja por ele não conhecer as estratégias para integrar o estudo da cultura ao da língua.

É importante que o professor procure enfocar, em suas aulas, a forma na qual uma língua é empregada na comunicação entre grupos sociais distintos, e quais as mudanças de registro e suas adequações aos diferentes contextos conversacionais. O mau uso de registros e estilos discursivos pode dar aos falantes nativos uma impressão desfavorável acerca do falante não nativo, impondo barreiras de origem cultural na comunicação. Notas de uso costumam aparecer em dicionários mais abrangentes. O reconhecimento da necessidade de se incluírem traços culturais às definições lexicográficas pode ser constatado em alguns dicionários encontrados hoje, no mercado, que em seu próprio título colocam a palavra "cultura". O Longman Language and Culture Dictionary, por exemplo, apesar de ser um dicionário padrão de língua, traz em suas páginas muitas informações culturais, não somente nas próprias definições, mas também em páginas coloridas específicas para este fim.

\section{Perfil dos consulentes}

É interessante indagar, neste momento, depois das devidas reflexões sobre uso do dicionário como material didático na aula de LEFE, quem é realmente o consulente de um dicionário. Como chegar a um consenso sobre quais as informações necessárias e suficientes para ele?

O usuário atribui ao dicionário o conhecimento inequívoco da língua, a fim de tirar suas dúvidas, transformando-o em um instrumento que remete à língua e à cultura, numa perspectiva sincrônica. $\mathrm{O}$ dicionário torna-se, portanto, uma norma explícita da cultura, exercendo um papel normativo dentro da comunidade dos falantes. 
Numa tentativa de esboçar o perfil desse consulente, Höfling (2000) entrevistou alguns tipos de consulentes, entre eles o estudante e o professor de $L E$ (de escola de idiomas, escola pública e privada de Ensino Fundamental, Médio e Ensino Superior), o tradutor/ intérprete e a secretária bilíngüe.

Dividindo os informantes deste estudo em duas categorias, profissionais de áreas afins e membros da área educacional (corpo docente e discente) - percebemos claramente diferenças quanto aos objetivos ao consultar um dicionário. A mais marcante diz respeito ao modo como consultam os dicionários. Os primeiros optam por dicionários técnicos e consultam o dicionário de maneira mais objetiva, ou seja, quase não utilizam os recursos que os dicionários oferecem, como, por exemplo, referências cruzadas, informações de natureza enciclopédica etc. O segundo grupo, mesmo apresentando mais dificuldade na consulta (principalmente os estudantes), exploram muito mais os recursos que os dicionários oferecem.

Em conformidade com a proposta de análise do perfil do consulente, Nesi (1999) realizou um estudo de natureza lexicográfica, cujo objetivo foi chegar a informações sobre o papel do dicionário no Ensino Superior, levando em conta reações de estudantes e professores. Segundo a autora, muitos estudantes chegam ao Ensino Superior sem nenhum tipo de "habilidade lexicográfica", ou seja, estudantes universitários sabem pouco sobre essa ferramenta de ensino. Segundo um dos informantes em seu estudo, dicionários são livros e estudantes estão cada vez mais relutantes para a leitura de livros. Além disso, um dos informantes apontou que enquanto os professores de LE assumem que as habilidades lexicográficas já tenham sido ensinadas por professores de língua materna, o inverso também é verdadeiro. A autora afirma, com base em seus dados, que os exercícios com dicionários em sala de aula não são práticas regulares entre professores e estudantes. Ambos crêem que tais exercícios são perda de tempo e causam desestímulo.

Levando em conta tais considerações e segundo os resultados do estudo feito por Höfling (2000), procuramos esboçar um perfil dos consulentes. Todos os consulentes, é evidente, afirmam possuir e consultar dicionários em casa, quando necessário. Entretanto, essa consulta não é tão freqüente. Os consulentes afirmam que não recorrem 
ao dicionário sempre que têm dúvidas, lançando mão de outros recursos para solucionar seus problemas. Quando o consultam, a situação, na maioria das vezes, é a de leitura de textos - os consulentes deparam-se com palavras que desconhecem e recorrem ao dicionário para a tradução. Contudo, nem sempre a informação que encontram é suficiente e satisfatória. Além disso, a maioria alega ler somente a definição do item, ou seja, qualquer outra informação presente no verbete poucas vezes é levada em conta.

Quanto ao tipo de definição lexicográfica, em contato com dicionários monolíngües, bilíngües e híbridos, os consulentes apontam as definições do dicionário híbrido como mais completas, ou seja, são as que mais ajudam no entendimento dos itens lexicais. Na verdade, o consulente está procurando mais do que simplesmente o equivalente da palavra em sua língua. A presença da descrição sucinta do item e de exemplos na língua-alvo faz com que o consulente prefira o dicionário híbrido aos outros, para seus propósitos. Além disso, em contato com dicionários monolíngües do inglês, nem sempre os consulentes apreendem o significado do item, fazendo com que este dicionário seja o último recurso em suas buscas. Quando instados a definir, com suas próprias palavras, alguns itens lexicais, os consulentes optam por uma definição que insere o item em uma classe genérica e traz informações relevantes quanto ao uso, sua descrição e localização física, além de informações de natureza enciclopédica.

Os consulentes consideram gráficos, figuras e tabelas no dicionário informações extremamente relevantes e importantes, assim como a presença de exemplos na definição lexicográfica. Mesmo depois de apreenderem o significado de um item, os consulentes tendem a ler os exemplos.

De acordo com os consulentes, a transcrição fonética é parte fundamental e necessária num verbete de um dicionário. Para obter essa informação, muitas vezes consultam os dicionários bilíngües com esse propósito, por conta de muitos deles trazerem a transliteração e não o alfabeto fonético internacional (AFI).

A maioria dos consulentes lê as informações gramaticais quando não sabe como usar a palavra e acha que esse tipo de informação é sempre útil e representa mais uma ferramenta no auxílio do entendimento do item lexical. Outra ferramenta usada pelos consulentes é a referência 
cruzada. Finalmente, informações sobre metáforas e expressões idiomáticas também são levadas em conta. Com isso, consideraremos agora um caso de ensino de LEFE.

\section{Um exemplo de fim específico: o caso do Turismo}

As características lingüísticas e funcionais que diferenciam um curso de língua comum de um curso de língua com fins específicos fazem com que, muitas vezes, o professor tenha dificuldade na elaboração das atividades. Segundo Sagnier (2004), dado o público notadamente heterogêneo, o professor de LEFE se vê, muitas vezes, obrigado a criar ou a complementar seu próprio material, de modo a explorá-lo numa seqüência coerente para atender às necessidades e ao ritmo de aprendizagem do público, não se esquecendo da infraestrutura oferecida pela instituição. Os novos métodos e manuais em inglês e, a partir dos anos 90, também os de francês, tentam suprir essa lacuna no mercado, fornecendo ao professor um material mais completo e eficiente.

No caso de um curso para estudantes de Turismo, por exemplo, a variedade de elementos a serem trabalhados engloba uma heterogeneidade de serviços e funções que podem ser desempenhados por um profissional da área. A questão lexical é de suma importância na hora de se pensarem as especificidades do curso de Turismo porque irá abarcar não somente uma terminologia específica desse setor, como também um léxico referente às artes, história, esportes, meio ambiente, empresas, economia e direito. Além disso, o perfil de atuação do profissional de turismo envolve o domínio de atividades comunicativas e de interação oral com turistas e outros profissionais, exigindo que o estudante domine as quatro habilidades comunicativas (compreensão e produção orais e escritas) e tenha um profundo conhecimento lexical e cultural. Frente a essa variedade, um curso que trabalhe apenas a leitura de textos da área, usando técnicas tradicionalmente adotadas em cursos "instrumentais", como skimming, scanning, simples identificação de cognatos e "falsos cognatos", entre outras, não consegue satisfazer a todas as necessidades.

Como verificou Sagnier (2004), atualmente, no mercado, podemos encontrar vários materiais didáticos para estudantes e profissionais, 
embasados na abordagem comunicativa, que procuram desenvolver todas as habilidades descritas acima. Para o Turismo, a série de materiais didáticos English for International Tourism, de Dubicka e O'Keeffe (2003), traz, em suas páginas, várias propostas de atividades para serem realizadas em sala de aula com o dicionário, como, por exemplo, desenvolvimento de vocabulário, pronúncia, identificação de aspectos gramaticais (como classificação gramatical, identificação de substantivos contáveis e não-contáveis etc.), prática de tradução, interpretação de texto, entre outras, em que é explicitamente indicado que o aluno utilize o dicionário naquele momento. O material traz ainda a indicação de um dicionário, da mesma editora, como sugestão para ser usado nessas atividades. Podemos, com isso, constatar que a utilização de dicionários em aulas de LEFE é desejável, incentivada pelos próprios idealizadores de materiais didáticos, como um complemento às atividades, e pode trazer muitos benefícios ao aprendizado. Para isso, é importante que o professor saiba como, quando e qual dicionário utilizar.

\section{O papel do professor de LE e sugestões de técnicas para o ensino de LEFE}

Os professores de LE têm como objetivo permitir ao aprendiz o domínio das competências lingüística, comunicativa e cultural numa LE geral (BERCHOUD, 2004). Para isso, é indispensável ter conhecimentos aprofundados da língua geral e dos elementos estruturais que a compõem. Contudo, ao tratarem de um domínio de especialidade, espera-se que os professores tenham conhecimento específico do assunto. Assim, o professor de uma LEFE, além de dominar a língua geral, deve sempre complementar sua (auto)formação nos domínios de especialidade com os quais trabalha, buscando apre(e)nder suas noções, seu léxico, seu estilo de comunicação.

De acordo com Challe (2004), isso não significa que o professor tenha obrigatoriamente de ser um especialista, mas deve estar familiarizado com as disciplinas, visto que seu nível de aprofundamento nunca será equivalente ao de um profissional experiente. Quando necessário, o professor pode buscar outros recursos, como associarse a um especialista para conhecer melhor seu campo de trabalho; 
consultar bibliografia especializada; participar de eventos da área, entre outros. Porém, cremos que, por vezes, o próprio contato com o público já possibilita esse intercâmbio.

O público necessariamente é formado por estudantes em via de especialização e por profissionais em busca de aprofundamento. Mesmo trabalhando com um público heterogêneo, o professor de LEFE tem a função de promover o conhecimento e estimular a autonomia dos aprendizes. Desse modo, eles poderão adquirir conhecimentos lingüísticos e, ao mesmo tempo, compartilhar conhecimentos referenciais específicos de suas áreas (CHALLE, 2004).

As tecnologias podem atender às necessidades tanto do professor quanto dos alunos. A Internet constitui um vasto campo de pesquisa. Por meio da rede, com o uso dos sítios de busca, é possível descobrir informações essenciais para o enriquecimento dos conhecimentos do professor e para que prepare materiais que sejam adequados aos pressupostos metodológicos. Há também os dicionários on-line, que podem servir para esclarecer dúvidas, mesmo de termos muito recentes.

É função do professor diferenciar as atividades quanto ao nível lingüístico dos aprendizes (básico, intermediário e avançado); quanto ao contexto educacional (Ensino Fundamental, Médio, Superior em Letras, em outras áreas que necessitem da língua estrangeira para fins específicos e para as escolas de idiomas) e, finalmente, quanto ao número de aprendizes, isto é, o professor tem que levar em conta a possibilidade de formação de grupos de trabalho ou de trabalho individual. Tendo em mente o contexto diversificado de atividades com dicionários em sala de aula, o professor pode selecioná-las adequadamente para o perfil específico e singular de cada classe de aprendizes.

Afirmamos veementemente que o maior trunfo do professor de LEFE é o conhecimento da língua e das estratégias de uso da mesma nas fronteiras dos domínios do conhecimento. Passamos, então, a apresentar sugestões de técnicas de como auxiliar o aprendiz a adquirir a LE, considerando os níveis lingüísticos (semântica, sintaxe, morfologia, fonética, pragmática), com apoio do uso do dicionário.

1) Leitura e interpretação de texto: a) estabelecer sempre os objetivos da leitura antes de qualquer atitude (o que se pressupõe que vai acontecer numa aula de LEFE); b) usar a estratégia da leitura para apreender apenas o tema geral, com as técnicas amplamente 
utilizadas nos cursos instrumentais; c) estimular a leitura com aprofundamento do assunto e, conseqüentemente, possibilitar ao aprendiz resolver as dificuldades de compreensão com o dicionário; d) promover discussão do tema para os aprendizes em todos os níveis, dando subsídios para que se tornem capazes de expressar sua opinião, seja na forma oral ou escrita.

2) O desenvolvimento de vocabulário: a) trabalhar com redes semânticas - apontar, nos textos, as relações entre os termos e verificar as semelhanças e distinções referentes à língua materna, utilizando o dicionário sempre que faltar o equivalente adequado; b) relacionar os elementos sinônimos e antônimos - descobrir sua importância na argumentação dos textos e verificar se o dicionário apresenta essa categoria nos verbetes; c) verificar a parte morfológica da língua - fornecer elementos que facilitem a compreensão de palavras, mesmo que estas não estejam na nomenclatura do dicionário; d) trabalhar com a questão dos cognatos e "falsos cognatos" - fazer os alunos trabalharem concretamente com o material. O dicionário fornece as respostas.

3) A gramática: a) observar a existência de compêndios gramaticais nos dicionários - se não houver, fornecer os elementos indispensáveis para a compreensão (pronomes, artigos, advérbios, preposições, conjunções), partindo sempre do material usado, mesmo que não tenha uma seqüência lógica e que não respeite uma progressão por nível de conhecimento; b) trabalhar com o sistema verbal da língua - ensinar a consulta de verbos nos dicionários (no caso do francês, em que, muitas vezes, a forma flexionada difere totalmente da forma infinitiva) e a correspondência temporal com a língua materna; c) procurar apontar as regularidades da língua - promover a memorização, mesmo que de maneira superficial, das estruturas gramaticais mais complexas.

4) A pronúncia: a) trabalhar com quadros de explicações de pronúncia existentes nos dicionários; b) apresentar o AFI e ensinar a compreender os símbolos, com o fim de ensinar a usar a transcrição fonética dos dicionários, sendo, nesse caso, recomendável que o aprendiz interessado em comunicação oral tenha um dicionário que forneça a transcrição fonética da nomenclatura. 
5) O uso de língua: a) indicar dicionários específicos (de turismo, de negócios etc.); b) identificar os aspectos culturais e contrastá-los com a cultura de origem dos alunos; c) simular situações específicas de comunicação em dupla ou em grupo e incentivar o uso do dicionário para codificação, entre outras.

\section{Considerações finais}

O aumento da procura por aulas de língua estrangeira para fins específicos configura-se em uma nova realidade. Conscientes da necessidade de novas pesquisas que enfoquem essa modalidade de ensino de línguas, apresentamos neste artigo algumas possibilidades de uso do dicionário como material didático em atividades durante a aula e também como material de apoio ao aluno que tem fins específicos para o aprendizado da LE. O dicionário é um dos materiais mais procurados por pessoas que decidem estudar outra língua. Não obstante, a falta de informações sobre qual dicionário comprar e como utilizá-lo acaba levando a uma frustração e desestímulo por parte do usuário. Acreditamos ser papel do professor indicar a seu aluno qual dicionário adquirir e como explorar ao máximo suas qualidades, levando em conta o perfil e as necessidades deste aluno. Mais do que isso, consideramos o dicionário um excelente material didático que deve ser utilizado também durante as aulas de LE. Para um bom aproveitamento desse material, é imprescindível que o professor saiba desenvolver diferentes atividades, explorando as várias possibilidades de uso do dicionário. Esperamos que as técnicas aqui descritas auxiliem o professor nesse propósito.

\section{Referências Bibliográficas}

BERCHOUD, M. J. Communication de spécialité, culture(s), mondialisation. Le français dans le monde / Recherche et applications, Paris, p.52-61, janv. 2004. Numéro spécial.

CHALLE, O. La place du FOS dans la formation tout au long de la vie. Le français dans le monde/ Recherche et applications, Paris, p.169-179, janv. 2004. Numéro Spécial. 
DUBICKA, I.; O'KEEFFE, M. English for International Tourism (preintermediate). Harlow: Longman, 2003.

HAENSCH, G. Tipología de las obras lexicográficas. In: HAENSCH, G. y otros. La lexicografía. De la Lingüística teórica a la lexicografía práctica. Madrid: Editorial Gredos, 1981. p. 95-187.

HÖFLING, C. Da análise crítica de definições de nomes concretos em Dicionários para uma proposta de definição padrão. Araraquara, 231 p. Dissertação (Mestrado em Letras) - FCL - UNESP, 2000.

HÖFliNG, C., TOSQUI, P., SILVA, M. C. P. O dicionário como material didático na aula de língua estrangeira. Intercâmbio, São Paulo: LAEL-PUC/ SP, v. 13, 2004. CD-ROM.

NESI, H. The specification of dictionary reference skills in Higher Education. In: HARTMAN, R. (Ed.). Dictionaries in language learning. Recommendations, National Reports and Thematic Reports from the TNP Sub-project 9: Dictionaries. Berlin: Free University Berlin, 1999. p. 53-66.

PANDOLFI, M. A.; TOSQUI, P. Cultura e sociedade no ensino de línguas para o Turismo. Anais do XX Congresso Brasileiro de Ciências da Comunicação. Porto Alegre, 2004, CD-ROM.

SAGNIER, C. Les méthodes et l'usage des méthodes en FOS: interêts, usages, limites. Le français dans le monde / Recherche et applications, Paris, p.96105, janv. 2004. Numéro Spécial.

TOSQUI, P. Advérbios Modalizadores-Subsídios para Dicionários Bilíngües. Araraquara, 144 p. Dissertação (Mestrado em Letras) - FCL - Unesp, 2002.

. O Dicionário Bilíngüe como Ferramenta de Ensino/Aprendizagem de uma Língua Estrangeira. Trabalbos em Lingüística Aplicada. Campinas: UNICAMP/IEL, Setor de Publicações, v. 40, p.101-114, 2002.

WRIGHT, J. Dictionaries. Oxford: Oxford University Press, 1998. 